\title{
Mindfulness and Quality of Innovation in Cloud Computing Adoption
}

\author{
John Otieno Oredo ${ }^{1} \&$ James Muranga Njihia ${ }^{2}$ \\ ${ }^{1}$ Faculty of Information Science and Technology, Kisii University, Kenya \\ ${ }^{2}$ School of Business, University of Nairobi, Kenya \\ Correspondence: John Otieno Oredo, Faculty of Information Science and Technology, Kisii University, Kenya. \\ E-mail: john.oredo@gmail.com
}

Received: September 1, 2014

Accepted: November 11, 2014

Online Published: December 20, 2014

doi:10.5539/ijbm.v10n1p144

URL: http://dx.doi.org/10.5539/ijbm.v10n1p144

\begin{abstract}
The emergence of cloud computing is quickly redefining the information technology (IT) and business landscape. Cloud computing involves delivery of IT infrastructure, software and platforms as a service to the end users. This IT acquisition model saves organizations from huge capital expenditures on IT and the burden of keeping a huge IT department to provide system support. Cloud computing as an IT innovation is steadily generating a lot of interest within IT innovation researchers and practitioners. Extant research in IT innovation has heavily relied on the dominant paradigm which explains and predicts innovation adoption on the basis of economic-rationalistic models. These models assume a direct relationship between an organization's innovator profile and the quantity of adoption in terms of earliness, frequency and extent of adoption. Further, they have always assumed a positive relationship between the quantity of innovation and quality of innovation. The advent of radical IT innovations like cloud computing calls for a rethinking of the dominant paradigm in terms of its efficacy in explaining innovative behaviors in organizations. Organizations hoping to adopt cloud computing are in need of a unifying IT innovation model that will help them discern whether, when and how to innovate. That is, they are concerned about the quality of innovation. This study proposes an IT innovation adoption model that incorporates the concept of mindfulness as a moderating factor between quantity of innovation and quality of innovation. The proposed conceptual model is a result of a thorough literature review of the IT innovation adoption research. This study, though conceptual, enriches cloud computing research by proposing an IT innovation model that suits its radical nature compared to other IT innovations. The proposed model once validated will also be of valuable use to practitioners and researchers interested in cloud adoption.
\end{abstract}

Keywords: mindfulness, cloud computing adoption, innovation

\section{Introduction}

Information Technology has always played the role of a disruptive force that somehow connects discontinuities and changes business models, ecosystems or even the world order. Cloud computing is another such phenomenon that has attracted increasing attention from both researchers and practitioners as a new paradigm of information technology (S. Yang \& Hsu, 2011). Cloud computing has been described as one of the technological shifts within the last decade (Wang, Rashid, \& Chuang, 2011) enabling a massive transformation of the entire computing industry in the $21^{\text {st }}$ century ("IDC Cloud," 2013). As a result, cloud computing has become a popular topic for blogging, white papers, workshops, conferences and even magazines (Armbrust et al., 2010).

An international study on key information technology and management issues ranked cloud computing as $2^{\text {nd }}$ and $3^{\text {rd }}$ in terms of top application and technology developments in 2011 and 2012 respectively (Luftman\&Zadeh, 2011; Luftman et al., 2012). Worldwide revenue from public IT cloud services exceeded $\$ 21.5$ billion in 2010 and will reach $\$ 72.9$ billion in 2015, representing a compound annual growth rate (CAGR) of $27.6 \%$ ("IDC Cloud," 2013). This rapid growth rate is over four times the projected growth for the worldwide IT market as a whole which stands at $6.7 \%$ ("IDC Cloud," 2013). This relative novelty and exploding growth of cloud computing makes it an exciting area for IT innovation research (H. Yang \& Tate, 2009). Cloud computing cannot be sufficiently understood as a standalone phenomenon in the IT market, but rather as a core ingredient of a larger transformation of the IT industry since it impacts the entire IT ecosystem. Cloud computing therefore makes a compelling business case on both technical and commercial aspects (KPMG, 2011).

The adoption and assimilation of IT innovation has been a key area of investigation within the information 
systems research community for the past two decades (S. Yang \& Hsu, 2011). These studies on IT innovation have been conducted mainly using economic-rationalistic models (Abu-Khadra \& Ziadat, 2012; Fidock \& Carroll, 2010; S. Yang \& Hsu, 2011). These economic-rationalistic models have been collectively referred to as the dominant paradigm (Benbasat \& Barki, 2007; Fichman, 2004). Studies using the dominant paradigm models have mainly focused on the relationship between the innovator profile of an organization and the quantity of innovation (timing, rate and implementation of IT innovation). These studies have been criticized for not being able to allow for complex interactions among the factors that go beyond simple linear or multiplicative effects (Fichman, 2004). The dominant paradigm models also assume that there is always a positive relationship between the quantity of innovation and the quality of innovation, also conceptualized as the performance outcomes (Fichman, 2004). Studies such as Ragin (1999) that used the innovation configuration perspective suggest that this may not be true.

The advent of cloud computing as a radical IT innovation, that has transformed how IT resources are acquired, provides an opportunity for IT innovation research to go beyond the dominant paradigm. While in the dominant paradigm, organizations must have certain characteristics (innovator profile) in order to innovate with technology successfully, Cloud computing provides new ways of acquiring technology that may not depend on the traditional innovator profile. Again, cloud computing is a multilayered innovation with several technologies and stakeholders whose successful adoption may not be explained by simple linear models. Researchers have argued that it is not possible to have a single theory that applies to all types of innovations (Baker, 2012) because innovations are of different types (Swanson, 1994). Given that the adoption of cloud computing is still at an early stage of development among OECD countries (OECD, 2010) and by extension developing countries, the main concern by organizations is reliability. This study proposes an IT innovation model that incorporates the theory of mindfulness in order to address the reliability concern in cloud adoption and to moderate the link between quantity of innovation and quality of innovation. This work responds to calls in IS literature for the incorporation of mindfulness in IT innovation research (B. S. Butler \& Gray, 2006; Fichman, 2004; Swanson \& Ramiller, 2004).

The remainder of this paper is organized as follows. First is a review of cloud computing concepts. This is followed by theoretical and empirical literature on IT innovation research. In the next section, we propose a conceptual framework showing the relationship amongst quantity of innovation, mindfulness and quality of innovation. The conclusion follows to reiterate the purpose of the study and possible future IT innovation research frontiers.

\section{Cloud Computing}

\subsection{The Genesis of Cloud Computing}

The history of Grids and the Cloud may be traced back to 1961 MIT centennial, when John McCarthy first exposed the idea of 'Utility Computing' and he predicted that it would become the basis of a new and important industry (Cafaro \& Aloisio, 2011). The idea of computing as a utility became the driving force behind the development of the Internet in the 1960s. The genesis of the use of the term 'Cloud Computing' is not clear as different literatures quote different dates. According to Lijun Mei et al (2008), the term cloud computing was first formulated in 1997 but its promotion and adoption has been slow until 2007. Some authors consider the birth of cloud computing to have been marked by the introduction of Amazon Elastic Compute Cloud (EC2) as a fee based commercial product (Weiss, 2007).

The utilization of computing resources as service rather than products started with the distribution of Information Technology (IT) infrastructure. Outsourced IT infrastructure services like Infrastructure as a Service (IaaS) has been around since at least the 1980s delivered by telecommunication companies and major IT outsourcers (Owens, 2010). Hosted applications in the form of Platform as a Service (PaaS) and Software as a Service (SaaS) were in vogue in the 1990s in the form of Application Service Provision (ASP) (Owens, 2010). Examples of ASP include email services like hotmail that emerged in the 1990s as a means of outsourcing applications as a service (Venters \& Whitley, 2012).

Early ASPs failed due to insufficient bandwidth and computing power (Venters \& Whitley, 2012); however the dot.com boom resulted in a large increase in global fiber optic networking dramatically reducing latency and costs (Hogendorn, 2011). The integration of various innovations gave birth to cloud computing. These innovations included grid computing, utility computing and virtualization of computer hardware resources, especially storage and computation power. The industrialization of IT infrastructure and the transfer of computing activities from individual PCs and private data centres to large external public data centres accessible over the internet became known as cloud computing (Venters \& Whitley, 2012). 
The idea of cloud computing and its disambiguation is still evolving. The term cloud computing has been defined in different ways by industry analyst firms, academics, IT companies and standards bodies. The definitions seem to favour specific interest of the defining stream. The definitions of cloud computing by some of the industry analyst firms are; 1) standardized IT capability (service, software or infrastructure) delivered via internet technologies in pay-per-use self service way by Forrester (Lecznar \& Patig, 2011); 2) Style of computing in which scalable and elastic IT-enabled capabilities are delivered as a service to external customers using internet technologies by Gartner (Daryl, Bittman, Austine, Cearley, \& Smith, 2008); and 3) A model for enabling ubiquitous, convenient, on-demand access to a shared pool of configurable computing resources(e.g. networks, servers, storage, applications and services) that can be rapidly provisioned and released by KMPG (KPMG, 2011). Industry analyst firms provide definitions that focus on the end user of cloud services.

The definitions of cloud computing provided by academics tend to focus on the components of cloud computing and the relationship between the suppliers and consumers of cloud services. For example, Venters and Whitley (2012)define cloud computing as a new computing paradigm that allows users to temporarily utilize computing infrastructure over the network, supplied as a service by a cloud provider at possibly one or more levels of abstraction. While Venters and Whitley abstracts the composition of a cloud environment in their definition, Buyya et al. (2009) emphasizes the components of a cloud environment. The last definition of cloud computing we consider is that of National Institute of Standards and Technology (NIST)-a standards body. It defines cloud computing as a model for enabling ubiquitous, convenient, on-demand network access to a shared pool of configurable computing resources (networks, servers, storage, applications and services) that can be rapidly provisioned and released with minimal management effort or service provider interaction (Venters \& Whitley, 2012). In this study we adopt the definition provided by NIST because it includes the components of cloud platform, the services it provides and the relationship between the cloud providers and consumers.

\subsection{Cloud Computing Ontology}

This section will introduce the organization of the cloud computing knowledge domain. This objective is achieved by understanding cloud computing in terms of its various components and the relationship amongst the components i.e. its ontology. Since cloud computing is an emerging innovation relying on several old and new technologies, its ontology can be broken down into various taxonomies. The role of taxonomies is to provide a structure and an organization to the knowledge of a field thus enabling researchers to study the relationships among concepts and, therefore, to hypothesize about these relationships (Nickerson, Varshney, \& Muntermann, 2013). Two cloud computing taxonomies are considered; cloud service models and cloud deployment models. Cloud computing characteristics discussed here are common to both the service and deployment models.

\subsubsection{Cloud Service Models}

In the course of cloud computing development, different classifications have been developed to capture its service layers. These layers have been referred to as cloud service models (Sriram \& Khajeh-Hosseini, 2010), cloud business models (Yang \& Hsu, 2011; Zhang, Cheng, \& Boutaba, 2010)and cloud architectural layer (Stanoevska-Slabeva \& Wozniak, 2010). The earliest classification known as the SPI model (Ahson \& Ilyas, 2011) stratified cloud services into software as a service (SaaS), platform as a service (PaaS) and infrastructure as a service (IaaS) (Yang \& Hsu, 2011; Zhang et al., 2010). The UCSB-IBM cloud ontology classified the cloud into five layers (Ahson \& Ilyas, 2011, p. 5). The first three layers are similar to the SPI model and the rest of the two layers are software kernel layer and the hardware/firmware layer. The moretechnical ontologies include Jackson's UCSB-IBM and Hoff's ontology (Ahson \& Ilyas, 2011).

The SaaS layer provides applications that run on the cloud eliminating the need to install and run the applications on the client computer (Marston, Li, Bandyopadhyay, Zhang, \& Ghalsasi, 2011). SaaS is a software that is owned, delivered and managed remotely by one or more providers and offered on a pay-per-use mode(Stanoevska-Slabeva \& Wozniak, 2010). PaaS facilitates the development and deployment of applications by providing operating system support and software development frameworks. This eliminates the cost and complexity of managing the underlying hardware and software layers. PaaS is a cloud service targeting developers. IaaS comprise computing resources like computational power (processors) and data servers that can be virtualized and instances provided as a service. Table 1 below gives a summary of service models and some of the service providers and their products. 
Table 1. Cloud service models

\begin{tabular}{lll}
\hline Service model & Providers & Services \\
\hline SaaS & SalesForce.Com & SalesForce.com \\
& Google & Google Apps \\
PaaS & Google & GoogleAppEngine \\
& Microsoft & Microsoft Azure \\
& SalesForce & Force.Com \\
IaaS & Amazon & Amazon EC2/S3 \\
& Zenith & Proud \\
\hline
\end{tabular}

\subsubsection{Cloud Deployment Models}

The cloud computing deployment models can be classified based on three features. These are physical location and distribution (Buyya, Goscinski, \& Broberg, 2011);and the owner of the cloud data centre (Ristol, 2010). In this sense, a cloud can be classified as private, public or hybrid (Buyya et al., 2011). Figure 1 below summarizes the various cloud deployment models.
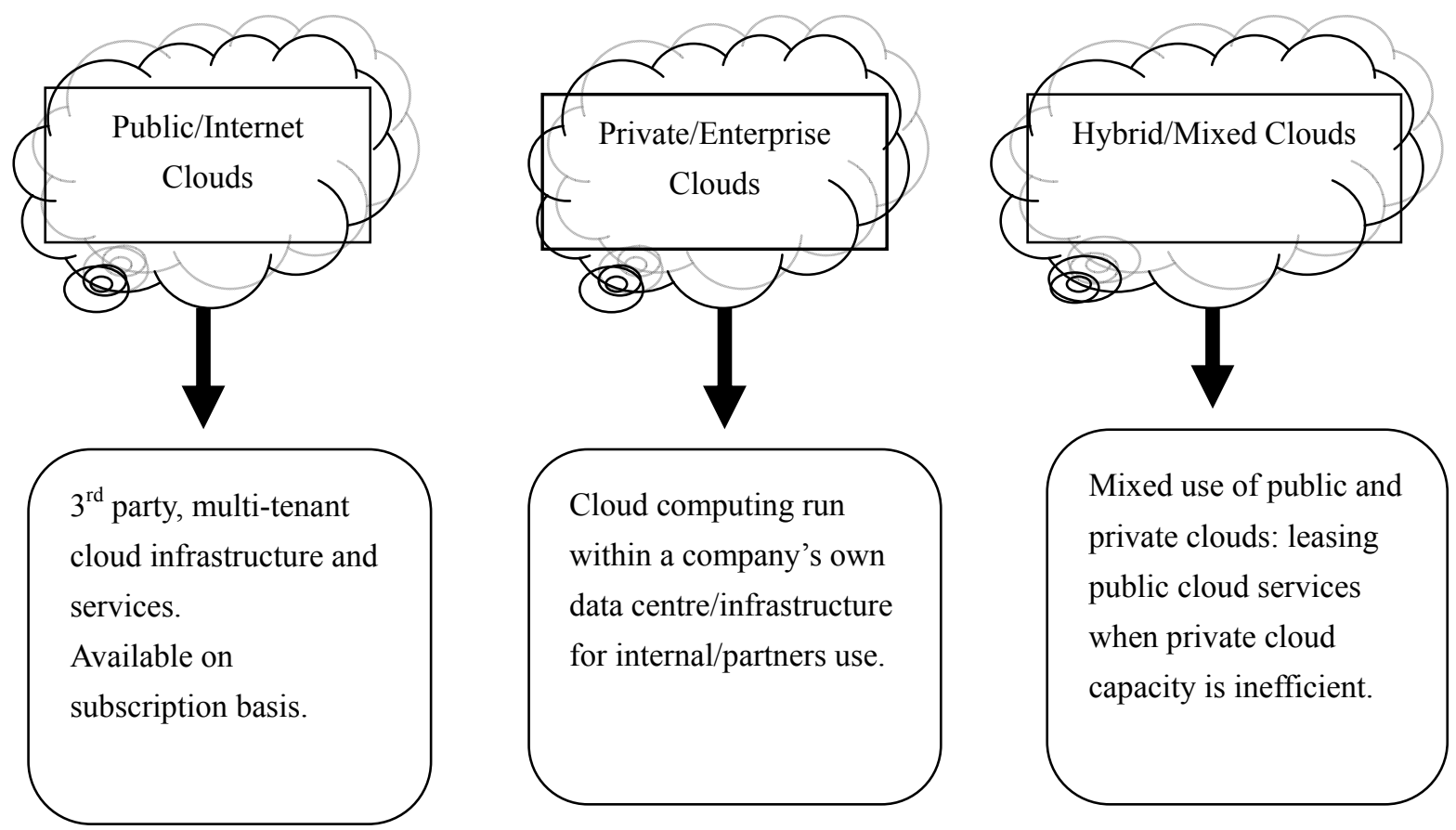

Figure 1. Cloud deployment models-adapted from (ristol, 2010)

The cloud deployment models are service-agnostic, implying that each service model can be deployed as private, public or hybrid cloud.

\subsubsection{Cloud Consumption Models}

Cloud computing offers a unique way to consume computation, network, storage and software resources. At the most fundamental level, cloud computing provides flexible real time access to a shared pool of computing resources like networks, servers, storage, applications and services (Oltsik, 2010). The provision of ITaaS made available by cloud computing is possible due to some characteristics of cloud computing. The characteristics of cloud computing are: 1) On-demand self services where a consumer can unilaterally provision computing capabilities without the provider's intervention; 2) Broad network access which provides capabilities over the internet for different users and services; 3 ) resource pooling by the service provider to be used on a need basis by the consumers; and 4) a measured service which consumers are billed just like electricity consumption.

\subsection{Cloud Benefits}

There are several compelling reasons for organizations to move operations toward cloud computing. Adoption of 
cloud computing requires very minimal upfront investment. Public cloud computing needs no capital expenditure because no hardware, software or network devices are purchased by the client (Mather, Kumaraswamy, \& Latif, 2009). With the flexibility that cloud computing offer, organizations can acquire computing and development services as needed on demand on a pay-per-use basis. This is possible because cloud computing resources can be rapidly allocated and de-allocated on demand (Zhang et al., 2010) thus lowering operating costs. Scalability of cloud computing allows organizations to demand computing resources and services on need basis. This is possible because infrastructure providers pool large amount of resources that are easily accessible depending on individual demand. Services hosted in the cloud are generally web-based and therefore, easily accessible through a variety of devices with internet connections (Zhang et al., 2010). Finally, cloud computing reduces business risks and maintenance expenses as these tasks are passed on to the cloud service provider (Zhang et al., 2010). The cloud service providers are often equipped with the right skills and equipment, making them also enjoy economies of large scale.

\subsection{Cloud Challenges}

There are several concerns users have with regard to the adoption of cloud computing. These challenges are seen as the main inhibitors to cloud adoption by organizations. Challenges or limitations of cloud computing are of technical, managerial and regulatory nature. Technical challenges include: 1) problems availability/reliability of cloud services and the measures to be taken when something goes wrong in the system or its components (Kim, 2009; Buyya et al., 2011; ERNST \& YOUNG, 2011), 2) lack of sufficient tools for integration/ Componentization of the various elements of the cloud (Mather et al., 2009, p. 230; Stanoevska-Slabeva \& Wozniak, 2010), 3) limited scope for customization so as to suit the specific needs of an organization (Stanoevska-Slabeva \& Wozniak, 2010; KPMG, 2011).

Managerial challenges to cloud computing include arise from the fact that an organization has to deal with many service and infrastructure vendors. This may create a problem of how to effectively and efficiently manage security and privacy of an organization's data (Kim, 2009; Buyya, Goscinski, \& Broberg, 2011). The provision of infrastructure and services by a vendor raises the fear of vendor lock-in (W. Kim, 2009; Mather et al., 2009, p. 228). Effective vendor management in order to get reliable services and prevent lock-in is become a challenge to many organizations (Ernst \& Young, 2011). Cloud users may face organizational inertia as shifting to a Cloud environment may change the role of IT departments in the organization, and the way operations are carried out in general. Organizations must therefore also focus on change management for successful adoption (KPMG, 2011). Cloud computing creates a situation where service providers and the consumers may not be within the same legal or regulatory jurisdiction. This situation is problematic currently due to compliance/regulatory ambiguity(Ernst \& Young, 2011; W. Kim, 2009; KPMG, 2011). These challenges can be collapsed into a single problem of cloud computing - the problem of reliability.

\subsubsection{Reliability in Cloud Computing}

The challenge of reliability in cloud computing arises from the fact that an organization's IT resources and data are no longer within proximity and its direct control but are with third party cloud service providers thus replacing locally hosted enterprise infrastructure. As a result, the first reliability issue is to manage performance variability that may arise from that replacement. The second reliability issue is to ensure that the cloud technical and service desires (Venters \& Whitley, 2012) are realized and managed for sustained superior outcomes. Furthermore, the third party cloud service providers rely on parallel and distributed systems to provide scalable and elastic IT capabilities over large scale networks. The tremendous complexity of these distributed applications deployed across diverse computing resources (Candidate, D, \& Fang, 2005) leads to both technical and organizational challenges to cloud adoption (Lin \& Chen, 2012) thus affecting its reliability.

In order for an organization to overcome these challenges and successfully migrate to the cloud, relevant research needs to be done in order to inform practitioners on the best practices of cloud adoption. The studies about cloud computing should be informed by well grounded theories to give them both explanatory and predictive potential. The next section reviews the theoretical and empirical literature in IT innovation in general and cloud adoption in particular.

\section{Literature Review}

Although cloud computing as an innovation has been widely adopted by the industry, the research on cloud computing is still at an early stage (Zhang et al., 2010). While there is an impressive amount of literature of cloud computing in computers science, there is still a dearth of literature in the IS area that looks at cloud computing (Marston et al., 2011). The cloud computing literature in computer science, for instance (Chow et al., 2009; Owens, 2010; Zhang et al., 2010) focus on the technical side of cloud computing. IS researchers, given 
that they have a background in the underlying technology and the associated business issues are better placed to bring forth a holistic perspective that is often lacking in technology literature (Marston et al., 2011). In this section, we first review IT innovation literature, followed by theoretical literature in IT innovation research with focus on cloud innovation and then proceed to look at the empirical studies on IT innovation.

\subsection{Information Technology (IT) Innovation}

Innovation can be defined as the creative process through which new products, services or production processes are developed for a business unit (Tushman \& Nadler, 2006). A key distinguishing feature of an innovation is newness. IT innovation is an innovation in digital and communications technologies and their applications (Swanson, 1994). Basically, IT innovations involve a technological component that is new to an industry or adopters. But most of the times, organizations need to develop new forms of cognition and organizational processes in order to leverage the technology. As a result, IT innovations normally penetrate organizations through integrating a complex network of interrelated innovations covering discovery of new computing capability, establishment of new development capabilities, and new services (Swanson, 1994). Lyytinen and Rose (2003) identifies three types of innovations as: 1) changes in system development, which involves new development tools and teams; 2) outcomes of development processes, which involves uses of IT to support the administrative core of the organization; and 3) IT base innovations, which includes new IT capability. Cloud computing manifests all these types of IT innovation characteristics.

\subsection{Theoretical Literature}

Theoretically, IS researchers have often relied on adoption, assimilation and diffusion of innovation perspectives to study cloud computing. Cloud computing, being a new paradigm in the acquisition and use of IT can be seen as an innovation. Cloud computing is considered an innovation because it is challenging our current understanding of the location and management of the IT infrastructure, the nature of product and service and business processes (Lin \& Chen, 2012). This understanding of innovation is supported by Rogers (1995) who defines an innovation as an idea, practice, or object that is perceived as new by an individual or other unit of adoption. Studying cloud computing through the lens of adoption and innovation theories enriches it in terms of research and practice. Swanson and Ramiller (2004) notes that the ultimate goal of innovation research is to provide guidance to managers on the question of "whether, when, and how to innovate with IT".

Many recent studies on technological innovation have focused on two confronting models: the economic-rational and social construction models (S. Yang \& Hsu, 2011). The economic- rational models explain IT innovation adoption and diffusion in terms of phases through which use of an IT artifact transitions - from the period prior to use through to continued or discontinued use (Fidock \& Carroll, 2010). For this reason, Fidock and Caroll (2010) refer to them as IT use life cycle theories. These theories have also been labeled "the dominant paradigm" (Benbasat \& Barki, 2007; Fichman, 2004; S. Yang \& Hsu, 2011). The sociological perspective emphasizes the social embeddedness of technological innovation. This approach stems from the desire to appear legitimate to powerful constituents or various stakeholders (S. Yang \& Hsu, 2011). The sociological perspective is mainly seen in terms of the institutional theories. The institutional theories posit that not every outcome is the result of a conscious decision making process, instead that argue that institutions are composed of cultural-cognitive, normative and regulative elements that together provide stability and meaning to social life (S. Yang \& Hsu, 2011).

\subsubsection{The Dominant Paradigm and Its Theories}

Theories in the dominant paradigm are typified by the desire to explain IT innovation using economic-rationalistic models. Under the dominant paradigm, it is assumed that organizations with a greater quantity of the "Right Stuff" will exhibit a greater quantity of innovation (Fichman, 2004). The right quantity of the right stuff has been conceptualized as the extent to which organizations possess certain characteristics - or operate in certain contexts - that increase the need for innovation and the ability to innovate successfully (Fichman, 2004). The quantity of innovation is assumed to be the extent to which an organization adopts innovation often, adopts them early and adopts them thoroughly (Fichman, 2001). Some of the popular theories in the dominant paradigm are discussed in the following paragraphs.

The Diffusion of Innovation Theory (DOI), also known as the Innovation Diffusion Theory (IDT) is based on the seminal work of Everett Rogers (1983). According to Rogers, the rate of adoption of innovation is impacted by five factors: relative advantage, compatibility, triability, observability and complexity. DOI being a life cycle model, explains change in reference to the sequence of phases through which the system of interest passes (Ven \& Poole, 1995). DOI and its associated five key attributes have been drawn on extensively in IS literature to explain innovation implementation success or adoption. Roger's DOI has been criticized mainly from three 
angles. It has been criticized, just like all the life cycle theories for not revealing the underlying mechanisms that generate the observed behavior (Fidock \& Carroll, 2010). Furthermore, most of the studies employing DOI have done so from a cross-sectional or factor based research thus ignoring the process-oriented nature of innovation diffusion (Fidock \& Carroll, 2010). The theory has also been judged as being poorly equipped to facilitate understanding of how different groups interact in the production and provision of an innovation(Abu-Khadra \& Ziadat, 2012). Nevertheless, DOI is one of the most widely used rational theories and there is a general agreement among researchers that it is a suitable and a valid theory for examining the process of adoption (Golding, Donaldson, Tennant, \& Black, 2008). Following DOI in an attempt to explain and predict user adoption of technology is the Technology Acceptance Model (TAM) by Davis (1989).

The origins of TAM can be traced to the Theory of Reasoned Action (TRA) (Fishbein \& Ajzen, 1975). TAM evolved from TRA with the goal of explaining the determinants of computer acceptance that is general, and capable of explaining user behavior across end-user computing technologies (Bradley, 2012). The two key variables in TAM perceived usefulness (PU) and perceived ease of use (PEOU). The theoretical support for the use of PU and PEOUcan be found in self-efficacy theory, the cost-benefit paradigm, and the adoption of innovation literature (Bradley, 2012). While TAM is referred to as the most influential and commonly employed theory in IS (Y. Lee, Kozar, \& Larsen, 2003), it has some weaknesses. Lee et al(2003) found out that the major limitation of TAM studies is self reportage. The studies did not measure actual usage but relied on the research subject to indicate usage. Furthermore, most of the studies used a single IS system in each research project limiting the generalizability of the results to other types of systems (Bradley, 2012). These limitations raise serious questions about the utility of TAM and related models like Unified Theory of Acceptance and Use of Technology (UTAUT) for understanding the life cycle of use and it is for these reasons and others that there have been widespread calls to go beyond TAM (Benbasat \& Barki, 2007; Fidock \& Carroll, 2010). Due to these weaknesses, some theories like the Technology-Organization-Environment (TOE)

The Technology-Organization-Environment (TOE) was created by Tomatzky and Fleischer to study the adoption of technological innovations (Abu-Khadra \& Ziadat, 2012). They believed that the process by which a firm adopts and implements technological innovations is influenced by the technological context, the organizational context and the environmental context. The technological construct describes both the technologies in use and the new technologies relevant to the firm. The organization construct refers to the descriptive measures about the organization characteristics and resources such as scope, size, degree of centralization, degree of formalization, managerial structures, human resources, amount of slack resources and linkage among employees. The environmental construct refers to the arena in which a firm conducts its business - its industry, competitors, the macroeconomic context and the regulatory environment. It has been found that TOE is appropriate for studying contextual factors that influence e-business assimilation and it can be used for studying different innovations (Abu-Khadra \& Ziadat, 2012). TOE has been used to study adoption of new technologies (for example, C.-P. Lee \& Shim, 2007; Henriksen, 2006; Pan \& Jang, 2008).There is still lack of substantial empirical research in cloud computing using TOE.

The theoretical approaches within the dominant paradigm like DOI, TAM, and TOE discussed above and their extensions, have dominated IT innovation research in the past two decades (Abu-Khadra \& Ziadat, 2012; Benbasat \& Barki, 2007; Looi, 2004). While the models of the dominant paradigm generally have reasonably worked well in answering the questions they are intended to answer (Fichman, 2004), their linear discourse has been criticized as "overrationalized" and fails to provide plausible explanations for the institutional and technical complexities of modern organizational environments (Abrahamson, 1991). Furthermore, they have been seen as being pro-innovation and adopts a perspective that privileges the new over the taken for granted, adoption over rejection and factor over process (Fidock \& Carroll, 2010). They fail, therefore, to take into account how an organization attends to innovations with reasoning grounded in its own facts and specifics (Weick \& Sutcliffe, 2001 ) in order to adopt the right innovation, at the right time and in the right way i.e. the aggregated innovation performance (Haner, 2002). It is time the IT innovation research move beyond the traditional quantity of innovation as the innovation outcome variable. Furthermore, current IT innovation research needs to take into account how the particularities of emerging complex ITs(Abu-Khadra \& Ziadat, 2012) like cloud computing and the complexities of modern organizational environments (S. Yang \& Hsu, 2011) are posing technical and organization challenges to adoption of IT innovations (Lin \& Chen, 2012).

\subsubsection{The Sociological Perspective}

The social perspective argues that the diffusion of IT innovation among organizations is socially constructed by the technology discourse, as well as shared norms, values and beliefs about the innovation (Yang \& Hsu, 2011). Some of the main theories in the sociological perspective are: the institutional theory, stakeholder theory, 
structuration theory and the organizing vision. The institutional theory is concerned with the influences that shape social and organizational structures, schemes, rules, norms, schemes and ultimately the behavior of social actors (Butler, 2012). The stakeholder holder theory provides the benefit of identifying who is key in the project and if and how they can be managed (Mishra \& Dwivedi, 2012). Closely related to the stakeholder theory is the structuration theory (ST). ST originates from social science and has been moulded to study technology and organizational driven change in the field of IS (Sharma, Barnett, \& Clarke, 2012).The organizing vision is a modification of the institutional theory and is tailored to understanding how social cognition drives the development, adoption and the diffusion of innovation in inter-organizational fields (Yang \& Hsu, 2011).

A major potential challenge in the use of most of the social perspective in IT adoption is their lack of focus on technology (Sharma et al., 2012). The IT artifact is an important pillar in IS and should therefore not be taken for granted and assumed to be unproblematic (Orlikowski \& Iacono, 2001). Radical IT innovations like cloud computing are fraught with various technology oriented challenges that impact on their adoption by organizations. The greatest technology oriented challenge is that of reliability. The next section briefly reviews reliability in IS.

\subsubsection{Reliability in IS Research}

An IS in the nature of cloud computing consists of a hierarchy of interconnected resources, objectives, perceptions and outcomes (Zahedi, 1987). To guarantee the success of such a system, its reliability becomes a major concern. The concept of reliability is hardly new. It is well discussed in literature regarding high reliability organizations, for example (Weick, Sutcliffe, \& Obstfeld, 1999). Organizational reliability has been defined as the capacity to produce collective outcomes of a minimum quality repeatedly (Hannan \& Freeman, 1984). Reliable performance is not merely the attainment of a desired outcome level but also the ability to control variance in the outcomes (B. S. Butler \& Gray, 2006; Zahedi, 1987). Cloud computing is still a new technology characterized by lack of standards (W. Kim, 2009), uncontrollable vendor behavior (Ernst \& Young, 2011) andintegration with existing architecture (Stanoevska-Slabeva \& Wozniak, 2010). It is therefore important that as businesses migrate to cloud computing, the process of migration and implementation should be managed in a manner that contributes to reliable aggregate performance.

While IS scholars have recognized that technical reliability is a factor in successful systems and have devised techniques to enhance reliability in such systems, the role of IS and organizational reliability has not been a major theme (B. S. Butler \& Gray, 2006). As a result, organizations are searching for managerial solutions to help them cope with these complex, chaotic and fragile (Butler \& Gray, 2006; Candidate et al., 2005) cloud environment to achieve reliable outcomes. Recently, there have been calls to consider mindfulness (Langer, 1989) in IS research (Butler \& Gray, 2006) and also in IT innovation (Swanson \& Ramiller, 2004). Mindfulness is an organizational cognition theory that has the potential of bridging the gap between the dominant and sociological theories in understanding radical IT innovations like cloud computing.

\section{Challenging the Dominant Paradigm}

The theoretical approaches within the dominant paradigm like DOI, TAM, and TOE discussed above and their extensions, have dominated IT innovation research in the past two decades (Abu-Khadra \& Ziadat, 2012; Benbasat \& Barki, 2007; Looi, 2004). The dominant paradigm models look at innovations in terms of what makes them more adoptable or look at organizations and what makes them more innovative by employing economic-rationalistic logic to link variables (Fichman, 2004). In this approach, the independent variable is the quantity of the "right stuff" and the dependent variable is the quantity of innovation. While the models of the dominant paradigm generally have reasonably worked well in answering the questions they are intended to answer (Fichman, 2004), the dominant paradigm has been criticized for being pro-innovation and adopts a perspective that privileges the new over the taken for granted, adoption over rejection and factor over process (Fidock\& Carroll, 2010). They fail, therefore, to take into account how an organization attends to innovations with reasoning grounded in its own facts and specifics (Weick \& Sutcliffe, 2001) in order to adopt the right innovation, at the right time and in the right way i.e. the aggregated innovation performance (Haner, 2002). It is time the IT innovation research move beyond the traditional quantity of innovation as the innovation outcome variable. Furthermore, current IT innovation research needs to take into account how the particularities of emerging complex ITs(Abu-Khadra \& Ziadat, 2012) like cloud computing and the complexities of modern organizational environments (S. Yang \& Hsu, 2011) are posing technical and organization challenges to adoption of IT innovations (Lin \& Chen, 2012).IT innovation needs to be understood in terms of hospitality. According to Ciborra (2002), hospitality describes the phenomenon of dealing with new technology as an ambiguous stranger. One possibility we explore in bridging this gap is to introduce an organizational cognition theory - mindfulness. 
Mindfulness treats technology in terms of hospitality - it connects the inside (organization) and the stranger (technology).

\subsection{Toward Innovation Mindfulness}

The salient reason for looking beyond the dominant paradigm is a need for an alternative stream of IT innovation research that gives us a fuller picture of what causes different sorts of innovative behaviours especially with emerging innovations like cloud computing. The dominant paradigm has had the unintended consequence of diverting IS researchers from taking a unifying theme of IT innovation that can help practitioners discern whether, when and how to innovate (Fichman, 2004).A potential opportunity for bridging this gap is by incorporating mindfulness (Weick\& Sutcliffe, 2001) to moderate the link between quantity of innovation and quality of innovation. In fact, mindfulness has been linked to making of sound judgments about whether, when and how to innovate (Swanson \& Ramiller, 2004). The theory of mindfulness originated from studies of high reliability organizations (Weick et al., 1999) and organizational cognition literature (B. S. Butler \& Gray, 2006). Incorporating mindfulness into existing IT innovation research enables its theorizing to benefit from fresh new insights from other fields of inquiry (Kock, 2010). The following section explains the theory of mindfulness and its constructs.

\subsection{The Theory of Mindfulness}

Studies of human systems reveal two strategies for achieving reliable performance: routine based reliability and mindfulness based reliability (B. S. Butler \& Gray, 2006). While routine based approaches focus on reducing situated human cognition as the cause of error, mindfulness based approaches focus on promoting highly situated human cognition as the solution to human and organizational reliability problems (Weick \& Sutcliffe, 2001). Mindfulness approaches hold that individuals' and organizations' ability to achieve reliable performance in changing environments depends on how they think: how they gather information, how they perceive the world around them, and whether they are able to change their perspective to reflect the situation at hand (Langer, 1989). In order to reflect the distinction between an individuals' and organizations' abilities Butler and Gray (2006) distinguish between individual and collective mindfulness.

\subsubsection{Individual Mindfulness}

According to Langer (1989), individual mindfulness refers to continuous scrutiny and refinement of expectations based on new experiences, appreciation of the subtleties of context, and identification of novel aspects context that can improve foresight and functioning. Mindfulness at the individual level emphasizes the ability to continuously create and use new categories in perception and interpretation of the world (Langer 1994, p.4 cited in Butler \& Gray, 2006). For individuals, mindfulness involves (1) openness to novelty, (2) alertness to distinction, (3) sensitivity to different, (4) awareness of multiple perspectives, and (5) orientation in the present (Sternberg 2000, cited in Butler \& Gray, 2006). The table below summarizes these attributes of individual mindfulness.

Table 3. Aspects of individual mindfulness (Matook \& Kautz, 2008)

\begin{tabular}{ll}
\hline Aspects & Characteristics \\
\hline $\begin{array}{l}\text { 1.Openness to novelty } \\
\text { 2. Alertness to distinction }\end{array}$ & $\begin{array}{l}\text { Ability to reason about and to cope with novel kinds of stimuli. } \\
\text { Ability to compare, contrast and judge about how things are the } \\
\text { same or different. } \\
\text { Awareness of situational characteristics to notice when and whether } \\
\text { 3. Sensitivity to different contexts }\end{array}$ \\
$\begin{array}{l}\text { a setting changes. } \\
\text { Appreciation of things from different and opposing points of view. } \\
\text { 5. Orientation in the present }\end{array}$ & $\begin{array}{l}\text { Individual's attention to their immediate situation and their actual } \\
\text { surroundings. }\end{array}$ \\
\hline
\end{tabular}

\subsubsection{Collective Mindfulness}

Collective mindfulness is also known as organizational mindfulness (B. S. Butler \& Gray, 2006).The relationship between individual mindfulness and organizational mindfulness is like individual learning and organizational learning (Matook \& Kautz, 2008). In collective mindfulness, existing expectations are continuously scrutinized 
and refined according to new

experiences in order to be able to invent new expectations for dealing with unprecedented situations to improve foresight and current functioning (Weick \& Sutcliffe, 2001). Weick and Sutcliffe go further to state aspects of organizational mindfulness as: (1) preoccupation with failure, (2) reluctance to simplify, (3) attention to operations, (4) commitment to resilience, and (5) migration of decision to expertise. The table below provides a summary of the various organizational/collective mindfulness aspects and their characteristics.

Table 4. Summary of organizational/collective mindfulness aspects and their characteristics

\begin{tabular}{ll}
\hline Aspect & Characteristics \\
\hline $\begin{array}{l}\text { 1).Preoccupation with failure } \\
\text { 2). Reluctance to simplify }\end{array}$ & $\begin{array}{l}\text { Utilization of errors and failures as a way of improvement. } \\
\text { Organizational aspiration to perceive problems from different points } \\
\text { of view. } \\
\text { Individuals' capability to have an integrated overall picture of } \\
\text { 3). Attention to operations }\end{array}$ \\
$\begin{array}{ll}\text { 4). Commitment to resilience } \\
\begin{array}{l}\text { 5). Under specification of structures (Migration of decisions to cope with problems and dangers as they occur. } \\
\text { expertise) }\end{array}\end{array}$ & $\begin{array}{l}\text { Migrating the problem to the experts who are most capable of } \\
\text { solving them, regardless of hierarchical levels. }\end{array}$ \\
\hline
\end{tabular}

\subsection{Re-Conceptualizing IT Innovation Variables: Incorporating Mindfulness}

In the dominant paradigm, it is assumed that organizations with a greater quantity of the right stuff will exhibit a greater quantity of innovation and such organizations are said to fit the innovator profile (Fichman, 2004). The figure below shows the conceptual framework of the dominant paradigm.

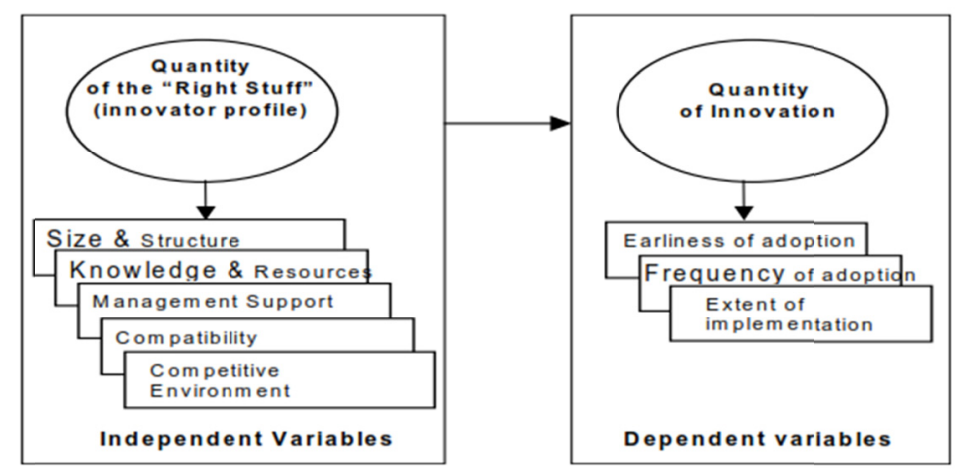

Figure 2. The dominant paradigm framework (Fichman, 2004)

While the dominant paradigm will be concerned with predicting which organization will be the first to adopt an innovation given its organizational characteristics (the right stuff), mindfulness seeks to explain how some organizations can resist an innovation that do not have any merit for them despite having the innovator profile. It turns out that models of the dominant paradigm do not consider ultimate outcomes or benefits of an innovation. The ultimate outcome of an IT innovation can be conceptualized as the quality of innovation (Fichman, 2004). In keeping with the view that mindful organizations will make better decisions throughout the innovation process, it could be posited that mindfulness will moderate the link between the quantity of innovation and the quality of innovation. We propose a new conceptual framework that consists of quantity of innovation, quality of innovation and organizational mindfulness. The conceptual framework adopted here follows the definition provided by Miles and Huberman (1994). They define a conceptual framework as a written or visual product that explains either graphically or a narrative form the key factors, concepts and variables and the presumed relationship amongst them. 


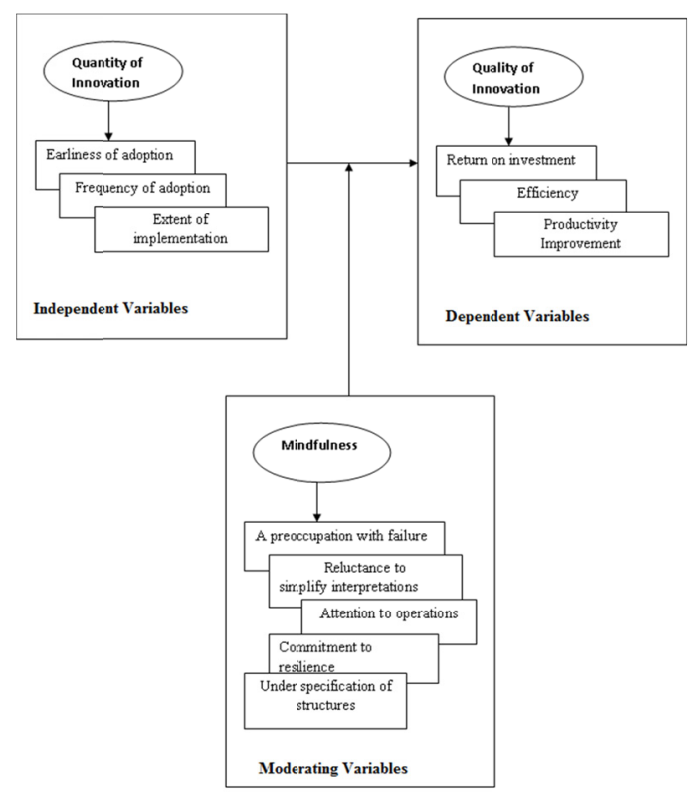

Figure 3. The conceptual framework (adapted from Fichman, 2004)

\subsubsection{The Independent Variables}

In the conceptual framework above, it is assumed that the quantity of innovation directly determines the quality of innovation. Variables in this construct include earliness of adoption, frequency of adoption and extent of implementation. Some studies that have employed this approach, for example, Dos Santos and Peffers (1995) have found a positive link between quantity of innovation and quality of innovation in the form of performance impacts. They reported that early ATM adopters and particularly first movers may have been able to improve profitability by increasing customer value (Santos \& Peffers, 1995, p. 243). On the effect of extent of implementation, Hitt et al. (2002) found that organizations with a greater breadth of innovation use achieved greater benefits when they examined the performance of ERP adopters and non-adopters thus linking extent of innovation implementation to quality of innovation.

\subsubsection{The Moderating Variables}

While some studies indicate a direct relationship between quantity of innovation and quality of innovation (Hitt et al., 2002; Santos \& Peffers, 1995), we hypothesize that organizations that exhibit greater mindfulness will have a greater quality of innovation when measured as outcome performance. This is because mindful organizations make innovation decisions that are grounded in their organizational facts and specifics.

\subsubsection{Preoccupation with Failure}

The first aspect of organizational mindfulness is preoccupation with failure. A preoccupation with failure focuses the organization on converting errors and failures into grounds for improvement, often by treating failures and near failures as indicators of the overall health of the entire system (B. S. Butler \& Gray, 2006). Apart from treating failures as indicators of the overall health of the system, effective organizations also conduct thorough analysis of near failures (Weick \& Sutcliffe, 2001). Cloud computing involves delivery of scalable and elastic IT-enabled capabilities as a service through internet technologies. This potential can only be realized through availability of high speed bandwidth access. And for cloud computing to support modern enterprises, its resources must be available 24/7. Even though locally hosted infrastructure are themselves fallible, successful cloud services must be able to match, if not exceed the availability of local data centres. Cloud services are known to experience availability failures or outages (Furht \& Escalante, 2010) and therefore still does not offer round the clock availability. Organizations adopting cloud computing must continuously monitor any failure or outage of cloud services. Further, they must also monitor any variation in service quality as a way of determining the overall health of the organization since it relies on services provided by the cloud service providers (CSPs).All the personnel in the organization should be encouraged to report even small variations in the services provided and significant organizational effort should be expended to review them (Weick \& Sutcliffe, 2001). Each aspect of availability should be carefully considered when engaging with a CSP, negotiated as part of the 
service level agreement (SLA) and tested in failover drills (Mather et al., 2009). Generally, the process of any IT innovation (like cloud computing) is itself prone to failure, and reflective attention to possibilities for failure in this domain also enlarges mindfulness (Swanson \& Ramiller, 2004).

\subsubsection{Reluctance to Simplify Interpretations}

Reluctance to simplify interpretation refers to a collective desire to continually see problems in different perspectives (B. S. Butler \& Gray, 2006). The mindful organization resists the temptation to settle into simplified and reproducible heuristics in its interpretation of events (Swanson \& Ramiller, 2004). A mindful organization realizes that complex responses are needed in complex environments (Weick, 1995 cited in Swanson \& Ramiller, 2004). Such a reluctance to simplify interpretations applies to organizations operating in a cloud environment in several ways. Cloud computing itself is a complex innovation with several service, deployment and consumption models (Zhang et al., 2010). Managing the interaction amongst these various service, deployment and consumption models pose a technological and contractual challenge for organizations (Marston et al., 2011). Reluctance to simplify interpretations therefore enables an organization to understand these challenges and problems from different perspectives. This increases the organization's chances of noticing and reacting appropriately to small anomalies and errors which reduces the likelihood of larger disastrous failures (Swanson \& Ramiller, 2004) especially in a cloud ecosystem consisting of CSPs, cloud enablers and cloud users

\subsubsection{Attention to Operations}

Sensitivity to operations implies that some individuals in the organization have developed an integrated overall picture of operations in the moment (B. S. Butler \& Gray, 2006).The mindful organization attends vigilantly to small and seemingly insignificant details in day to day operations (Swanson \&Ramiller, 2004). This is because catastrophes usually accumulate from minor errors and random events. Organizations adopting cloud computing have cited lack of standards as a major concern (Marston et al., 2011). In the absence of standards, organizations must pay keen attention to every process since they cannot easily be automated.In the traditional setting, the main stakeholders are the providers and the consumers. Cloud computing adds new range of stakeholders, for example, regulators and enablers. This kind of setup requires personnel who understand how all these stakeholders interact in the cloud ecosystem.

\subsubsection{Commitment to Resilience}

A commitment to resilience refers to the tendency to cope with dangers and problems as they arise through error detection and error containment (B. S. Butler \& Gray, 2006). This approach is in contrast to anticipation- a case where organizations deal with surprises by weeding them out in advance (Weick et al., 1999). This anticipation is achieved through planning and design of contingency plans for every possible unfavourable outcome. Commitment to resilience takes recognition that anticipation through planning and contingency measures is always incomplete. Resilience favours improvisation over planning, adaptation over routine, and effectiveness over efficiency (Swanson \& Ramiller, 2004). In the context of cloud computing, commitment to resilience is likely to assume a significant role in ensuring reliability in the entire cloud ecosystem. The cloud environment is vulnerable to domino effects. The domino effect is due to the fact that the cloud ecosystem comprises a network of devices, services and organizations. These networks must be orchestrated so as to provide user services transparently. An interruption in any of the networks will cascade to the rest of the cloud ecosystem. Cloud adoption challenges like security (Buyya et al., 2011; W. Kim, 2009) and availability (Buyya et al., 2011; Ernst \& Young, 2011; W. Kim, 2009) are joined at the hip. A security problem like denial of service attack (DOS) will lead to data unavailability. This interrelationship of various networks in a cloud environment leads to uncertainty and unpredictability of possible challenges that may arise in a cloud ecosystem. Business disaster and recovery in a cloud environment should focus on managing the unexpected. Managing the unexpected require that organizational business continuity strategies create a context and culture in which individuals and organizational units are better able to practice resilience and reliability in the face of unexpected events (B. S. Butler \& Gray, 2006).

\subsubsection{Under Specification of Structure}

In this attribute of mindfulness, hierarchical rank is subordinated to expertise and experience. It involves migrating a problem to the experts who are most capable of solving them, regardless of hierarchical levels (Weick et al., 1999). Under specification of structure can further be viewed as the readiness to relax formal structure so that authority for action can flow in times of crisis to the individuals and the units having the requisite expertise to deal with the problem at hand (Swanson \& Ramiller, 2004). Cloud computing is a diverse phenomenon with several challenges including but not limited to security and privacy, vendor lock-in, regulatory ambiguity (W. Kim, 2009), integration, customization (Stanoevska-Slabeva \& Wozniak, 2010),cultural resistance 
and transition (KPMG, 2011). The expertise needed to address these challenges will naturally reside in different individuals and units of the organization. This implies that the requisite expertise is heterogeneous and dispersed, and that the authority for action must flow readily to different units within the organization. When an outage of service arises in a cloud environment, those affected will turn to others in an effort to understand what the anomaly means. This turn is a subtle loosening of hierarchy in favour of expertise (Weick\& Sutcliffe, 2001).

\subsection{The Dependent Variable}

The quality of innovation, which is taken as the dependent variable, can also be conceptualized as performance impacts (Fichman, 2004). The quality of innovation is defined as the extent to which an organization has adopted the right innovation, at the right time, and in the right way (Haner, 2002). Studies interested in measuring innovation quality have more often used performance impacts as a proxy. For example, Haner (2002) used return on investment, efficiency, and productivity improvement as measures for quality of innovation. The logic is that if a beneficial result has been achieved after adopting an innovation, then the quality of the decisions as what, when and how must have been good.

\section{Conclusion}

Cloud computing is an IT innovation that is changing how individuals and organizations acquire and use IT.The innovation is moving IT from a capital expenditure (CAPEX) to an operational expenditure (OPEX). It implies that an organization's IT needs is provided by a third party on a pay-as-you-need basis. While the shift to cloud computing has tremendous benefits to business organizations, its adoption is presenting organizations with challenges. The main challenge is that of reliability, arising from the fact that cloud computing platform is a complex network involving different players. The challenge of reliability if not managed well can threaten the quality of the innovation. The dominant paradigm, which has so far informed IS research in IT innovation, may not be the best model to explain cloud adoption. This is because cloud computing is a radical IT innovation. Further, research in IT innovation, indicates that no single theory can be used to explain all innovations. In this study, we propose an alternative conceptual model that can explain and predict successful cloud adoption. We explore the concept of mindfulness as used in high reliability organizations and organizational behavior literature to understand how an organization can make cloud adoption decisions that take into consideration its specifics and context for maximum performance outcome. The study is a response to calls for IS research to borrow relevant theories from other disciplines to enrich its theoretical repertoire. It further contributes to theory building in cloud computing research. This study provides insight to organizations that have adopted or in the process of adopting cloud computing with regard to when and how to adopt cloud computing; and what aspects of cloud computing to adopt.

\section{References}

Abrahamson, E. (1991). Managerial Fads and Fashions: The Diffusion and Rejection of Innovations. The Academy of Management Review, 16(3), 586-612. http://dx.doi.org/10.2307/258919

Abu-Khadra, H., \&Ziadat, K. (2012).ERP Diffusion and Assimilation Using IT-Innovation Framework.In Y. K. Dwivedi, M. R. Wade, \& S. L. Schneberger (Eds.), Information Systems Theory (pp. 159-184).New York: Springer.

Ahson, S., \& Ilyas, M. (2011).Cloud computing and software services: theory and techniques. Boca Raton, FL: CRC Press.

Armbrust, M., Fox, A., Griffith, R., Joseph, A. D., Katz, R., Konwinski, A., \&Zaharia, M. (2010). A view of cloud computing. Commun. ACM, 53(4), 50-58. http://dx.doi.org/10.1145/1721654.1721672

Baker, J. (2012). The Technology-Organization-Environment Framework. In Y. K. Dwivedi, M. R. Wade, \& S. L. Schneberger (Eds.), Information Systems Theory (pp. 231-245).New York: Springer.

Benbasat, I., \&Barki, H. (2007).Quo vadis TAM?Journal of the Association for Information Systems, 8(4). Retrieved from http://aisel.aisnet.org/jais/vol8/iss4/16

Bradley, J. (2012). If We Build It They Will Come? The Technology Acceptance Model. In Y. K. Dwivedi, M. R. Wade, \& S. L. Schneberger (Eds.), Information Systems Theory (pp. 19-36).Springer New York.

Butler, B. S., \& Gray, P. H. (2006).Reliability, Mindfulness, and Information Systems.MIS Quarterly, 30(2), 211-224. http://dx.doi.org/10.2307/25148728

Butler, T. (2012). Institutional Change and Green IS: Towards Problem-Driven, Mechanism-Based Explanations. In Y. K. Dwivedi \& S. L. Schneberger (Eds.), Information Systems Theory (pp. 383-407). New York: Springer. 
Buyya, R., Goscinski, A., \& Broberg, J. (2011). Introduction to Cloud Computing. In Cloud computing: principles and paradigms. Hoboken, N.J.: Wiley.

Buyya, R., Yeo, C. S., Venugopal, S., Broberg, J., \& Brandic, I. (2009). Cloud computing and emerging IT platforms: Vision, hype, and reality for delivering computing as the 5th utility. Future Generation Computer Systems, 25(6), 599-616. http://dx.doi.org/10.1016/j.future.2008.12.001

Cafaro, M., \& Aloisio, G. (2011).Grids, Clouds, and Virtualization. In M. Cafaro \& G. Aloisio (Eds.), Grids, Clouds and Virtualization (pp. 1-21).London: Springer.

Candidate, R. L. P. D., \& Fang, M. (2005).Reliability management for information system.Journal of Shanghai University (English Edition), 9(3), 268-274. http://dx.doi.org/10.1007/s11741-005-0091-1

Chow, R., Golle, P., Jakobsson, M., Shi, E., Staddon, J., Masuoka, R., \& Molina, J. (2009).Controlling data in the cloud: outsourcing computation without outsourcing control. In Proceedings of the 2009 ACM workshop on Cloud computing security(pp. 85-90).ACM. Retrieved from http://dl.acm.org/citation.cfm?id=1655020

Ciborra, C. (2002). The Labyrinths of Information: Challenging the Wisdom of Systems. USA: Oxford University Press.

Daryl, P., Bittman, T., Austine, T., Cearley, D., \& Smith, D. (2008).Cloud Computing: Defining and Describing an Emerging Phenomenon. Gartner Research.

Davis, F. D. (1989). Perceived Usefulness, Perceived Ease of Use, and User Acceptance of Information Technology. MIS Quarterly, 13(3), 319-340. http://dx.doi.org/10.2307/249008

Ernst \& Young.(2011). Cloud Computing Issues and Impacts. EYGM Ltd.

Fichman, R. G. (2001). The Role of Aggregation in the Measurement of IT-Related Organizational Innovation. MIS Quarterly, 25(4), 427-455. http://dx.doi.org/10.2307/3250990

Fichman, R. G. (2004). Going Beyond the Dominant Paradigm for Information Technology Innovation Research: Emerging Concepts and Methods. Journal of the Association for Information Systems, 5(8).

Fidock, J., \& Carroll, J. (2010). Theorising about the lifecycle of IT use: An appropriation perspective (pp. 1-23). Presented at the 5th Information Systems Foundations Workshop: Theory Building in Information Systems, ANU e-Press (The Australian National university).

Fishbein, M., \& Ajzen, I. (1975).Belief, attitude, intention, and behavior: an introduction to theory and research. Reading, Mass.: Addison-Wesley Pub. Co.

Furht, B., \& Escalante, A. (2010).Handbook of cloud computing. New York: Springer.

Golding, P., Donaldson, O., Tennant, V., \& Black, K. (2008). An Analysis of Factors Affecting the Adoption of ICT By MSMEs in Rural and Urban Jamaica. ECIS 2008 Proceedings. Retrieved from http://works.bepress.com/opal_donaldson/1

Haner, U. E. (2002).Innovation quality-a conceptual framework. International Journal of Production Economics, 80(1), 31-37. http://dx.doi.org/10.1016/S0925-5273(02)00240-2

Hannan, M. T., \& Freeman, J. (1984).Structural Inertia and Organizational Change.American Sociological Review, 49(2), 149-164. http://dx.doi.org/10.2307/2095567

Henriksen, H. Z. (2006). Motivators for IOS Adoption in Denmark: Journal of Electronic Commerce in Organizations, 4(2), 25-39. http://dx.doi.org/10.4018/jeco.2006040102

Hitt, L. M., Wu, D. J., \& Zhou, X. (2002). Investment in Enterprise Resource Planning: Business Impact and Productivity Measures. J. Manage. Inf. Syst., 19(1), 71-98.

Hogendorn, C. (2011). Excessive(?) entry of national telecom networks, 1990-2001. Telecommunications Policy, 35(11), 920-932. http://dx.doi.org/10.1016/j.telpol.2011.09.003

IDC Cloud. (2013). Retrieved January $\quad 6, \quad 2013$, from http://www.idc.com/prodserv/idc_cloud.jsp\#.UOlQX6wvAxr

Kim, W. (2009). Cloud Computing: Today and Tomorrow. The Journal of Object Technology, 8(1), 65.http://dx.doi.org/10.5381/jot.2009.8.1.c4

Kock, N. F. (2010). Evolutionary psychology and information systems research a new approach to studying the effects of modern technologies on human behavior. New York; London: Springer.

KPMG. (2013). The Cloud-Changing the Business Ecosystem. Retrieved January 7, 2013, from 
http:/www.kpmg.com/in/en/issuesandinsights/articlespublications/pages/thecloud-changingthebusinessecos ystem.aspx

Langer, E. J. (1989). Mindfulness. Reading, Mass.: Perseus Books.

Lecznar, M., \& Patig, S. (2011). Cloud Computing Providers: Characteristics and Recommendations. In G. Babin, K. Stanoevska-Slabeva, \& P. Kropf (Eds.), E-Technologies: Transformation in a Connected World (pp. 32-45). Springer Berlin Heidelberg.

Lee, C. P., \& Shim, J. P. (2007). An exploratory study of radio frequency identification (RFID) adoption in the healthcare industry. European Journal of Information Systems, 16(6), $712-724$. http://dx.doi.org/10.1057/palgrave.ejis.3000716

Lee, Y., Kozar, K. A., \& Larsen, K. R. (2003). The Technology Acceptance Model: Past, Present and Future. Communications of the Association for Information Systems, 12.

Lin, A., \& Chen, N.C. (2012). Cloud computing as an innovation: Percepetion, attitude, and adoption. International Journal of Information Management, 32(6), 533-540. http://dx.doi.org/10.1016/j.ijinfomgt.2012.04.001

Looi, H. (2004). A Model of Factors Influencing Electronic Commerce Adoption among SMEs in Brunei, Darussalam. International Journal of Information Technology, 10(1), 72-87.

Luftman, J., \&Zadeh, H. S. (2011).Key information technology and management issues 2010-11: an international study.Journal of Information Technology, 26(3), 193-204. http://dx.doi.org/10.1057/jit.2011.3

Luftman, J., Zadeh, H. S., Derksen, B., Santana, M., Rigoni, E. H., \& Huang, Z. (David). (2012). Key information technology and management issues 2011-2012: an international study. Journal of Information Technology, 27(3), 198-212. http://dx.doi.org/10.1057/jit.2012.14

Lyytinen, K., \& Rose, G. M. (2003). The Disruptive Nature of Information Technology Innovations: The Case of Internet Computing in Systems Development Organizations. MIS Quarterly, 27(4), 557-596.

Marston, S., Li, Z., Bandyopadhyay, S., Zhang, J., \& Ghalsasi, A. (2011). Cloud computing-The business perspective. Decision Support Systems, 51(1), 176-189. http://dx.doi.org/10.1016/j.dss.2010.12.006

Mather, T., Kumaraswamy, S., \&Latif, S. (2009). Cloud security and privacy: an enterprise perspective on risks and compliance. Farnham: O’Reilly.

Matook, S., \& Kautz, K. (2008). Mindfulness and Agile Software Development. ACIS 2008 Proceedings. Retrieved from http://aisel.aisnet.org/acis2008/58

Mei, L., Chan, W. K., \& Tse, T. H. (2008). A Tale of Clouds: Paradigm Comparisons and Some Thoughts on Research Issues.In IEEE Asia-Pacific Services Computing Conference, 2008. APSCC '08 (pp. 464-469). http://dx.doi.org/10.1109/APSCC.2008.168

Miles, M. B., \& Huberman, A. M. (1994). Qualitative data analysis: an expanded sourcebook. Thousand Oaks: Sage Publications.

Mishra, A., \& Dwivedi, Y. K. (2012). Stakeholder Theory and Applications in Information Systems. In Y. K. Dwivedi, M. R. Wade, \& S. L. Schneberger (Eds.), Information Systems Theory (pp. 471-488).New York: Springer

Nickerson, R. C., Varshney, U., \&Muntermann, J. (2013).A method for taxonomy development and its application in information systems. European Journal of Information Systems, 22(3), 336-359. http://dx.doi.org/10.1057/ejis.2012.26

OECD. (2010). Annex B. Reaping the Benefits of Cloud Computing, Web 2.0 and Open Data: OECD Country Experiences. In OECD, Denmark: Efficient e-Government for Smarter Public Service Delivery (pp. 225-238). OECD Publishing.

Oltsik, J. (2010). What's Needed for Cloud Computing? ESG Inc.

Orlikowski, W. J., \& Iacono, C. S. (2001). Research Commentary: Desperately Seeking the "IT" in IT Research-A Call to Theorizing the IT Artifact. Retrieved February 21, 2014, from http://pubsonline.informs.org/doi/abs/10.1287/isre.12.2.121.9700

Owens, D. (2010). Securing Elasticity in the Cloud. Queue, 8(5), 1010-1016. http://dx.doi.org/10.1145/1794514.1794516 
Pan, M. J., \& Jang, W. Y. (2008). Determinants of the Adoption of Enterprise Resource Planning within the Technology-Organization-Environment Framework: Taiwan's Communications Industry. Journal of Computer Information Systems, 48(3).

Ragin, C. C. (1999). Using qualitative comparative analysis to study causal complexity. Health Services Research, 34(5 Pt 2), 1225-1239.

Ristol, S. (2010).Grid and cloud computing: a business perspective on technology and applications. Heidelberg: Springer.

Rogers, E. (1983). Diffusion of Innovation. New York.

Rogers, E. M. (1995). Diffusion of innovations. New York: Free Press.

Santos, B. L. D., \& Peffers, K. (1995). Rewards to Investors in Innovative Information Technology Applications: First Movers and Early Followers in ATMs. Organization Science, 6(3), 241-259.

Sharma, U., Barnett, J., \& Clarke, M. (2012). Using Concepts from Structuration Theory and Consequence of Modernity to Understand IS Deployment in Health-Care Setting. In Y. K. Dwivedi, M. R. Wade, \& S. L. Schneberger (Eds.), Information Systems Theory (pp. 131-142).New York: Springer.

Sriram, I., \& Khajeh-Hosseini, A. (2010).Research Agenda in Cloud Technologies (arXiv e-print No. 1001.3259). Retrieved from http://arxiv.org/abs/1001.3259

Stanoevska-Slabeva, K., \& Wozniak, T. (2010). Cloud Basics - An Introduction to Cloud Computing. In K. Stanoevska-Slabeva, T. Wozniak, \& S. Ristol (Eds.), Grid and Cloud Computing (pp. 47-61).Berlin Heidelberg: Springer.

Swanson, E. B. (1994). Information Systems Innovation among Organizations. Management Science, 40(9), 1069-1092.

Swanson, E. B., \&Ramiller, N. C. (2004).Innovating mindfully with information technology.MIS Q., 28(4), 553-583.

Tushman, M., \& Nadler, D. (2006).Organizing for Innovation. California Management Review. Retrieved from http://www.hbs.edu/faculty/Pages/item.aspx?num=3543

Ven, A. H. van de, \& Poole, M. S. (1995). Explaining Development and Change in Organizations. The Academy of Management Review, 20(3), 510-540. http://dx.doi.org/10.2307/258786

Venters, W., \& Whitley, E. A. (2012). A critical review of cloud computing: researching desires and realities. Journal of Information Technology, 27(3), 179-197. http://dx.doi.org/10.1057/jit.2012.17

Wang, W., Rashid, A., \& Chuang, H.-M. (2011). Toward the Trend of Cloud Computing. Journal of Electronic Commerce Research, 12(4), 238-242.

Weick, K. E., \& Sutcliffe, K. M. (2001). Managing the unexpected: assuring high performance in an age of complexity. San Francisco: Jossey-Bass.

Weick, K. E., Sutcliffe, K. M., \& Obstfeld, D. (1999).Organizing for high reliability: Processes of collective mindfulness. Research in Organizational Behavior, 21, 81-123.

Weiss, A. (2007). Computing in the clouds. Net Worker, 11(4), 16-25. http://dx.doi.org/10.1145/1327512.1327513

Yang, H., \& Tate, M. (2009). Where are we at with Cloud Computing?: A Descriptive Literature Review. ACIS 2009 Proceedings. Retrieved from http://aisel.aisnet.org/acis2009/26

Yang, S., \& Hsu, C. (2011).The Organizing Vision for Cloud Computing in Taiwan. Journal of Electronic Commerce Research, 12(4), 257-271.

Zahedi, F. (1987).Reliability of Information Systems Based on the Critical Success Factors-Formulation. MIS Quarterly, 11(2), 187-203. http://dx.doi.org/10.2307/249362

Zhang, Q., Cheng, L., \& Boutaba, R. (2010).Cloud computing: state-of-the-art and research challenges. Journal of Internet Services and Applications, 1(1), 7-18. http://dx.doi.org/10.1007/s13174-010-0007-6 


\section{Copyrights}

Copyright for this article is retained by the author(s), with first publication rights granted to the journal.

This is an open-access article distributed under the terms and conditions of the Creative Commons Attribution license (http://creativecommons.org/licenses/by/3.0/). 